\title{
Performance assessment and clinical experience (PACE) scorecards for anesthesiology residents: a post-implementation physician survey
}

\author{
Alexander J. Lingley, MSc (1) • Ryan McGinn, MD, MSc • Christopher L. Pysyk, MD • \\ Gregory L. Bryson, MD, MSc $\cdot$ Daniel G. Dubois, MD
}

Received: 7 July 2020/Revised: 9 July 2020/Accepted: 10 July 2020/Published online: 23 July 2020

(C) Canadian Anesthesiologists' Society 2020

\section{To the Editor,}

Paralleling adoption of competency-based medical education and electronic health records (EHRs) has spurred interest in developing novel tools for the evaluation of physician performance. The use of EHRs allows multiple process and patient outcome metrics to be employed for educational improvement initiatives. The objective nature of automated performance analysis stands to provide a valuable adjunct to subjective feedback, the current predominant form of evaluation in clinical education.

Self-documented logs are commonly employed to audit resident learning experiences and infer progression towards competency. Nevertheless, a pilot project at our institution revealed disparity in cumulative clinical exposure tracked between logbooks and an EHR. ${ }^{1}$ To explore the utility of EHRs in clinical evaluation, we provided a scorecard summarizing annual clinical activities and performance of anesthesiology residents at the University of Ottawa (Figure). Data were extracted from the Anesthesia Information Management System (AIMS). A similar scorecard was previously developed for staff anesthesiologists at The Ottawa Hospital. ${ }^{2}$

Electronic supplementary material The online version of this article (https://doi.org/10.1007/s12630-020-01766-6) contains supplementary material, which is available to authorized users.

\footnotetext{
A. J. Lingley, MSc

Faculty of Medicine, University of Ottawa, Ottawa, ON, Canada

R. McGinn, MD, MSc - C. L. Pysyk, MD .

G. L. Bryson, MD, MSc - D. G. Dubois, MD ( $\square)$

Department of Anesthesiology and Pain Medicine, University of

Ottawa, Ottawa, ON, Canada

e-mail:dadubois@toh.ca
}

An existing post-implementation survey, which assessed staff anesthesiologists' perceptions of performance scorecards, was modified for this study. ${ }^{2}$ Our survey comprised 11 items including seven Likert scales (ranging from strongly disagree to strongly agree) and four qualitative questions (eAppendix in the Electronic Supplementary Material). Four volunteers validated the survey using the Burns clinical sensibility tool. Scorecards and survey invitations were distributed via email to all enrolled anesthesiology residents in June $2019(n=42)$. This study was approved on 22 July 2019 by The Ottawa Health Science Network Research Ethics Board (OHSNREB; 20,190,124-01H); participation was voluntary and responses were anonymized.

Using a modified Dillman method, ${ }^{3}$ we obtained a response rate of $(17 / 42 ; 40 \%)$. Most residents agreed/ strongly agreed that the scorecards were personally interesting $(15 / 17 ; 88 \%)$, valuable for professional development $(13 / 17 ; 76 \%)$, an effective measure of clinical experience $(12 / 17 ; 71 \%)$, and influential for future practice $(12 / 17 ; 71 \%)$. Most residents also agreed/ strongly agreed that scorecards were preferable to logbooks $(12 / 17 ; 71 \%)$ but only $41 \%$ (7/17) of respondents agreed/ strongly agreed that scorecards were an effective measure of clinical performance.

The benefits of EHR-derived assessment are severalfold. Applying quantitative data to indicators of care enables self-assessment of performance and experience relative to peers or training program goals. Scorecards are cost-effective and relieve clerical burden associated with manual logging. Additionally, passive feedback may positively influence practice behaviours as serial administration of similar scorecards was associated with more frequent administration of intraoperative anti-emetics and reduced postoperative nausea/vomiting in a previous 
Figure Sample anesthesiology resident performance assessment and clinical experience (PACE) scorecard for postgraduate years (PGY) $1-$ 5. Data were extracted from a perioperative electronic health record, the Anesthesia Information Management System (AIMS). Gray column shows departmental totals at The Ottawa Hospital (TOH) for comparison

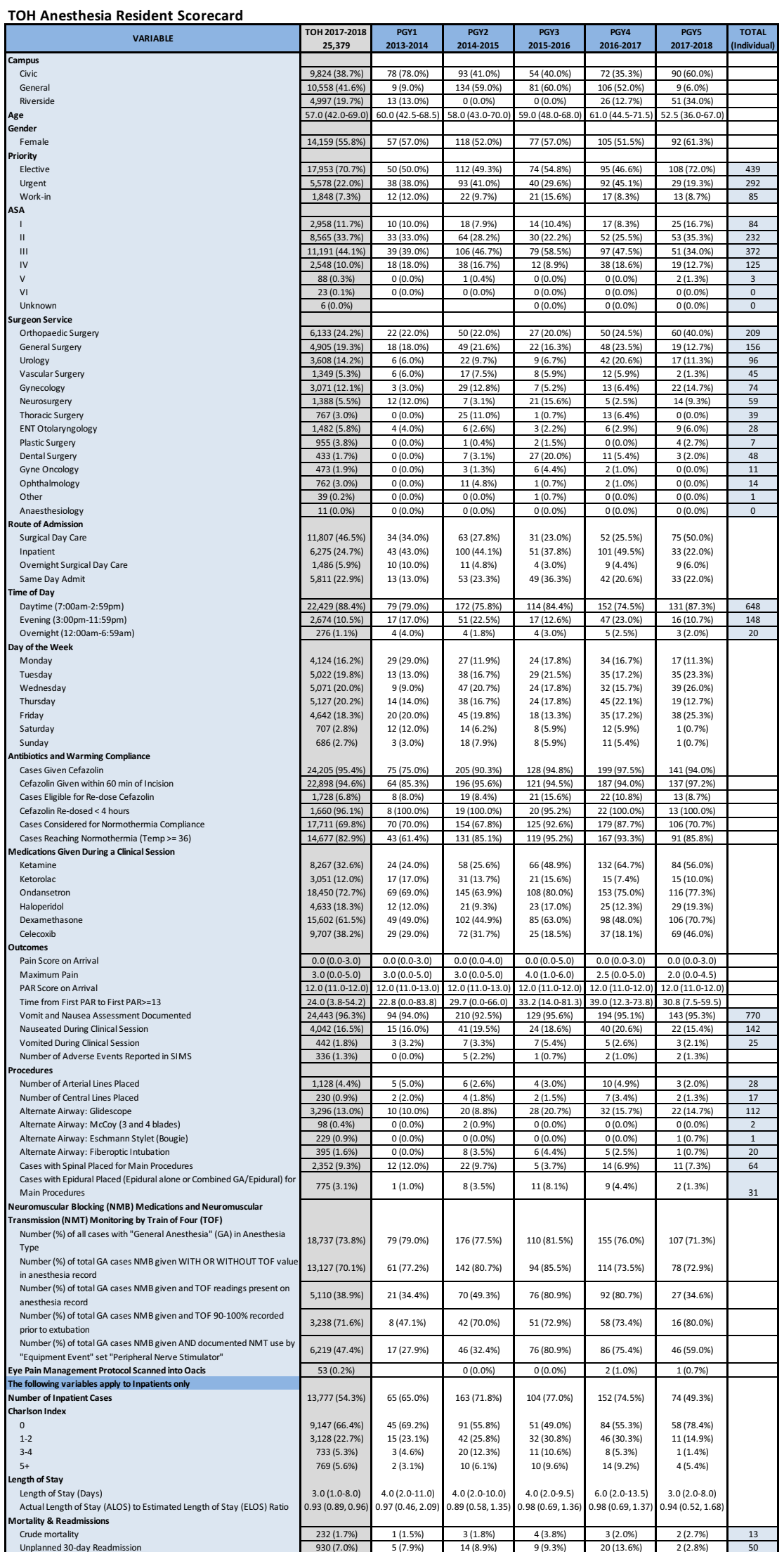


study. ${ }^{4}$ The ability to include patient outcome data, which was completely deidentified and compliant with the Ontario Patient Privacy Act, provides tangible feedback to residents on the most clinically relevant aspects of their practice.

Despite advantages, the acceptability of scorecards as a measure of performance was low in our cohort and among staff anesthesiologists at the same institution. ${ }^{2}$ A previous qualitative study identified limitations to acceptance of EHR-based assessment. ${ }^{5}$ Foremost was perceived incompleteness of data and the tendency to falsely attribute outcomes to an individual, masking team-level contributions. ${ }^{5}$ These limitations highlight the importance of employing EHR-mediated assessment adjunctively with other modalities including direct observation for comprehensive trainee evaluation.

In summary, this study indicates potential utility of EHR-derived scorecards during anesthesiology training. Serial administration with monitoring and coaching via academic advisors may inform whether scorecards influence practice behaviours or correlate with progression through residency. If so, the trajectory of residents and programs could be estimated with appropriate interventions enacted to improve medical education and quality of care.

Disclosures None.
Funding statement Funding was provided by Department of Innovation in Medical Education, University of Ottawa, Ottawa ON and University of Ottawa Faculty of Medicine Summer Student Bursary.

Editorial responsibility This submission was handled by Dr. Hilary P. Grocott, Editor-in-Chief, Canadian Journal of Anesthesia.

\section{References}

1. McGinn R, Lingley AJ, McIsaac DI, et al. Logging in: a comparative analysis of electronic health records versus anesthesia resident-driven logbooks. Can J Anesth 2020. https:// doi.org/10.1007/s12630-020-01761-x

2. Wheeler K, Baxter A, Boet S, Pysyk C, Bryson GL. Performance feedback in anesthesia: a post-implementation survey. Can J Anesth 2017; 64: 681-2

3. Thorpe C, Ryan B, McLean SL, et al. How to obtain excellent response rates when surveying physicians. Fam Pract 2009; 26: 658

4. Pysyk CL, Corsi DJ, Boet S. The potential for anesthesiologist practice feedback to reduce postoperative vomiting in an academic centre. Can J Anesth 2019; 66: 609-10.

5. Sebok-Syer SS, Goldszmidt M, Watling CJ, Chahine S, Venance $S L$, Lingard L. Using electronic health record data to assess residents' clinical performance in the workplace: the good, the bad, and the unthinkable. Acad Med 2019; 94: 853-60.

Publisher's Note Springer Nature remains neutral with regard to jurisdictional claims in published maps and institutional affiliations. 